\title{
Fenologia, morfologia floral e visitantes de Psychotria brachypoda (Müll.Arg.) Britton (Rubiaceae) em uma área de Floresta Atlântica, Sudeste do Brasil
}

\author{
Lorena Coutinho Nery Fonseca ${ }^{1}$, Elisângela Medeiros de Almeida² e Maria Alice Santos Alves ${ }^{2,3}$
}

Recebido em 24/10/2006. Aceito em 25/04/2007

\begin{abstract}
RESUMO - (Fenologia, morfologia floral e visitantes de Psychotria brachypoda (Müll. Arg.) Britton (Rubiaceae) em uma área de Floresta Atlântica, Sudeste do Brasil). No presente estudo foram descritos o padrão fenológico, biologia floral, visitantes florais mais freqüentes e taxa de formação de frutos de Psychotria brachypoda, em uma área de Floresta Atlântica. O padrão de floração foi anual e intermediário, ocorrendo entre agosto e janeiro. A produção de frutos maduros ocorreu de março a julho/2004 e de fevereiro a maio/2005. O comprimento e o diâmetro da corola das flores brevistilas foram maiores que das longistilas. Apesar de não ter havido hercogamia recíproca exata, houve sobreposição entre as alturas dos estigmas das flores longistilas com os estames das brevistilas e vice-versa. O néctar apresentou maior concentração média de açúcares às $06: 30 \mathrm{~h}(33 \%)$ e menor às $14: 30 \mathrm{~h}(26 \%)$. Flores cujo néctar foi coletado ao longo do dia produziram em média três vezes mais néctar que as flores que tiveram o néctar coletado apenas no final do dia. Foram encontrados 24 indivíduos brevistilos e 25 longistilos, indicando que a população é isoplética. Os principais visitantes florais foram machos e fêmeas do beija-flor Thalurania glaucopis, abelhas da tribo Trigonini e do gênero Euglossa, três espécies de lepidópteros, um díptero e um coleóptero. Houve formação de frutos verdes em 13,3\% do total de flores marcadas e a taxa de produção de frutos foi similar entre os morfotipos florais. É provável que o principal polinizador de P. brachypoda seja o beija-flor T. glaucopis porque ele visita com freqüência muitas flores de diferentes indivíduos, provavelmente transferindo pólen entre eles.
\end{abstract}

Palavras-chave: Psychotria, heterostilia, polinizadores, fenologia, Floresta Atlântica

\begin{abstract}
Phenology, floral morphology and visitors of Psychotria brachypoda (Müll. Arg.) Britton (Rubiaceae) in Atlantic Forest, southeastern Brazil). In this paper, the phenological pattern, floral biology, most frequent floral visitors and fruit set of Psychotria brachypoda are described. This study was carried out in Atlantic forest from October 2003 to September 2005. Flowering was annual and intermediate, occurring from August to January. Mature fruit production occurred from March to July 2004 and from February to June 2005. Corolla length and diameter of thrum flowers were larger than those of pin flowers. Although stigma length corresponded approximately to stamen length in each morph, exact reciprocal hercogamy did not occur. The nectar was more concentrated at $06: 30 \mathrm{~h}(33 \%)$ and more diluted at 14:30h (26\%). Flowers in which nectar was collected throughout the day had about three times more nectar than flowers in which nectar was collected once at the end of the day. There were 24 plants with thrum flowers and 25 plants with pin flowers, indicating an isopletic population. The main floral visitors were females and males of the hummingbird Thalurania glaucopis, bees of the tribe Trigonini and of the genus Euglossa, three Lepidoptera species, one Diptera species and one Coleoptera. Fruit was produced in $13.7 \%$ of the total number of marked flowers, with similar production in both morphs. Thalurania glaucopis is probably the most important pollinator of $P$. brachypoda, because it often visits many flowers from different individuals of $P$. brachypoda, probably transferring pollen among them.
\end{abstract}

Key words: Psychotria, heterostyly, pollinators, phenology, Atlantic forest

\section{Introdução}

A fenologia de espécies vegetais estuda a periodicidade e a duração de eventos como a emissão foliar, a floração e a frutificação, fornecendo informações que permitem a análise da dependência destes eventos fenológicos com fatores bióticos e abióticos (Newstrom et al. 1994; Almeida \& Alves 2000; SanMartin-Gajardo \& Morellato 2003; Ramos \& Santos 2005). A observação fenológica, obtida de forma sistemática, reúne informações sobre o estabelecimento de espécies, o período de crescimento, de reprodução e a disponibilidade de recursos alimentares, como néctar e frutos, para a fauna

\footnotetext{
1 Programa de Pós-Graduação em Ecologia, Universidade Federal do Rio de Janeiro, Rua São Francisco Xavier, 524, $20550-011$ Rio de Janeiro, RJ, Brasil

2 Universidade do Estado do Rio de Janeiro, Departamento de Ecologia, Rua São Francisco Xavier 524, 20550-011 Rio de Janeiro, RJ, Brasil (masa@uerj.com)

3 Autor para correspondência: loricnf@yahoo.com
} 
(Morellato \& Leitão Filho 1992; Almeida \& Alves 2000; SanMartin-Gajardo \& Morellato 2003).

A família Rubiaceae é um dos mais importantes componentes do sub-bosque das florestas neotropicais (Gentry \& Emmons 1987; Laska 1997), estando entre as cinco famílias de maior riqueza de espécies em Floresta Atlântica (Pereira \& Araújo 2000). O gênero Psychotria é pantropical e composto principalmente por arbustos (Hamilton 1990) com muitas espécies apresentando flores heterostílicas, que são visitadas e/ou polinizadas por insetos e aves (Ganders 1979; Monteiro et al. 1991; Stone 1996; Castro \& Araújo 2004; Coelho \& Barbosa 2004; Teixeira \& Machado 2004; Lopes \& Buzato 2005; Ramos \& Santos 2006).

A heterostilia é um polimorfismo floral geneticamente controlado, caracterizado pela presença de duas (distilia) ou três (tristilia) formas morfológicas, que diferem quanto à altura dos estigmas e estames (Ganders 1979; Barret 1992). A maior parte das espécies heterostílicas são distílicas, apresentando uma forma com estames curtos e estilete longo (longistila) e outra com estames longos e estilete curto (brevistila) (Ganders 1979; Richards \& Koptur 1993; Stone 1996; Lau \& Bosque 2003). Espera-se que a reciprocidade na altura de estigma e anteras de um morfo em relação ao outro favoreça a ocorrência de polinização cruzada e diminua os cruzamentos entre morfos iguais (Ganders 1979; Barret et al. 2000). Flores heterostílicas são polinizadas por insetos, principalmente abelhas, mas também por moscas, mariposas, borboletas, besouros, beija-flores e vespas (Ganders 1979; Stone 1996; Almeida \& Alves 2000; Castro \& Oliveira 2002; Castro \& Araújo 2004; Coelho \& Barbosa 2004; Teixeira \& Machado 2004; Lopes \& Buzato 2005; Ramos \& Santos 2006) que se alimentam do pólen e/ou néctar destas flores.

No presente estudo descrevemos o padrão fenológico, a biologia floral, os visitantes florais mais freqüentes e a taxa de formação de frutos de Psychotria brachypoda (Müll. Arg.) Britton, uma espécie rica em alcalóides com atividade analgésica (Leal \& Elisabetsky 1996) que ocorre naturalmente em sub-bosque de Floresta Atlântica no sudeste do Brasil (SanMartin-Gajardo \& Morellato 2003; L.C.N. Fonseca, comunicação pessoal).

\section{Material e métodos}

O estudo foi realizado ao longo de uma trilha com $800 \mathrm{~m}$ de comprimento, com alcance visual de $5 \mathrm{~m}$ para cada lado, em uma área pouco perturbada de
Floresta Atlântica, próxima à Vila Dois Rios, Ilha

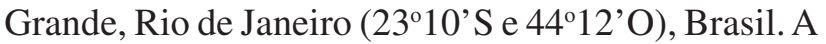
ilha possui aproximadamente 19.000 ha com vegetação em diferentes estágios de regeneração (Araujo \& Oliveira 1988; Oliveira 2002). A altitude da área de estudo variou de 140 a $260 \mathrm{~m}$, a altura do dossel de 25 a $30 \mathrm{~m}$ e o diâmetro das árvores foi de até $1,20 \mathrm{~m}$ (Vera y Conde, comunicação pessoal). O clima da região é quente-úmido com temperatura média anual de $23{ }^{\circ} \mathrm{C}$ e pluviosidade anual de aproximadamente $2.200 \mathrm{~mm}$ (dados fornecidos pela Fundação Instituto de Desenvolvimento Econômico e Social do Rio de Janeiro).

As observações das fenofases foram realizadas uma vez por mês entre outubro/2003 e setembro/2005. Foram registrados o número de flores abertas, de frutos maduros e a presença de frutos imaturos em 35 indivíduos de $P$. brachypoda marcados ao longo da trilha. Para avaliar a razão de morfotipos brevistilos e longistilos na área de estudo, identificou-se o tipo floral de todos os indivíduos encontrados em floração ao longo da trilha, totalizando 49 indivíduos.

Para o estudo da morfologia floral de P. brachypoda foram medidos o comprimento e o diâmetro da corola, a altura máxima dos estames e do estigma de 44 flores longistilas e 37 brevistilas, utilizando-se paquímetro $( \pm 0,1 \mathrm{~mm})$. A altura do estigma foi medida desde a base da corola até a altura máxima que o estigma alcançava e a altura dos estames foi medida através da escolha aleatória de um dos estames da flor, que era medido da base da corola até a altura máxima alcançada. Para medir o volume de néctar produzido ao longo do dia e sua concentração de açúcares, 30 flores ( 15 longistilas e 15 brevistilas) foram previamente ensacadas e no dia seguinte o néctar foi retirado com microseringa graduada $( \pm 0,1 \mu \mathrm{L})$, a cada 2 horas, de 6:30 h até 16:30 h. Também foi retirado, por volta de 16:00 h, o néctar acumulado de 26 flores que permaneceram o dia todo ensacadas, desde a pré antese. A porcentagem de açúcares no néctar foi medida com auxílio de refratômetro de bolso $( \pm 0,5 \%$, variando de 0 a $50 \%$ Brix).

Para registrar a freqüência dos potenciais polinizadores, foram realizadas 63 horas de observação focal em 12 indivíduos de P. brachypoda, entre 06:00 h e 17:30 h, com intervalos de $30 \mathrm{~min}$. Foram registrados a espécie visitante, o número de visitas e o número de flores visitadas. Os beija-flores foram identificados através de guia de campo (Grantsau 1989) e as abelhas foram coletadas e identificadas por especialistas. Foram marcadas 1.409 flores sob condições naturais 
(sem manipulação), que foram inspecionadas mensalmente de setembro/2003 a fevereiro/2004 para o registro do número de frutos imaturos formados para estimar a eficiência da polinização pelos visitantes florais em flores longistilas e brevistilas.

Após testes da normalidade dos valores de altura máxima dos estigmas e estames, comprimento, largura e diâmetro das corolas, foi aplicado o Teste-t para variáveis independentes (Zar 1999) objetivando avaliar diferenças entre flores longistilas e brevistilas. Foi aplicada regressão linear para avaliar se havia relação entre o número de visitas observadas ao longo do dia, realizadas pelos visitantes florais, e o volume de néctar coletado ao longo do dia. Estes testes estatísticos foram aplicados com o auxílio do programa Statistica 6.0 Copyrightã StatSoft. Inc. 1984-2001. As médias apresentadas são acompanhadas de \pm desvio padrão.

\section{Resultados}

As inflorescências de $P$. brachypoda foram terminais com flores tubulares, simpétalas, sinsépalas, nectaríferas, com o lado externo da corola lilás e o interno branco e amarelo. A antese ocorreu por volta de 06:00 h, quando as anteras já estavam abertas e o pólen disponível. Por volta de 17:00 h a corola apresentou-se escurecida e senescente. As flores duraram apenas um dia.

O comprimento da corola das flores brevistilas $(15,78 \mathrm{~mm} \pm 1,46 ; \mathrm{n}=37)$ foi maior $(\mathrm{t}=2,39 ; \mathrm{p}=0,02)$ que o das flores longistilas $(15,04 \mathrm{~mm} \pm 1,33 ; \mathrm{n}=44)$. $\mathrm{O}$ diâmetro das flores brevistilas $(2,44 \mathrm{~mm} \pm 0,33$; $\mathrm{n}=37)$ também foi maior $(\mathrm{t}=2,05 ; \mathrm{p}=0,04)$ que o das longistilas $(2,27 \mathrm{~mm} \pm 0,4 ; \mathrm{n} 44)$. Houve sobreposição entre os valores das alturas dos estigmas das flores longistilas com os estames das brevistilas e vice-versa, mas não ocorreu hercogamia recíproca exata, ou seja, a altura média dos estigmas das flores brevistilas $(10,16 \mathrm{~mm} \pm 0,98, \mathrm{n}=37)$ diferiu $(\mathrm{t}=3,35 ; \mathrm{p}=0,002)$ da dos estames das longistilas $(11,11 \mathrm{~mm} \pm 1,15, \mathrm{n}$ =43), assim como a altura média dos estigmas das flores longistilas $(15,54 \mathrm{~mm} \pm 0,4, \mathrm{n}=44)$ diferiu $(\mathrm{t}=2,63 ; \mathrm{p}=0,013)$ da dos estames das brevistilas $(14,59 \mathrm{~mm} \pm 1,58, \mathrm{n}=37)$ (Fig.1). Foram encontrados 24 indivíduos brevistilos e 25 longistilos, indicando que a população é isoplética.

A produção de néctar foi maior na parte da manhã, diminuindo ao longo do dia (Fig. 2). O néctar apresentou maior concentração média de açúcares às $6: 30 \mathrm{~h}(33 \%)$ e menor às $14: 30 \mathrm{~h}(26 \%)(\mathrm{n}=7)$. As flores que tiveram o néctar coletado ao longo do dia produziram em média
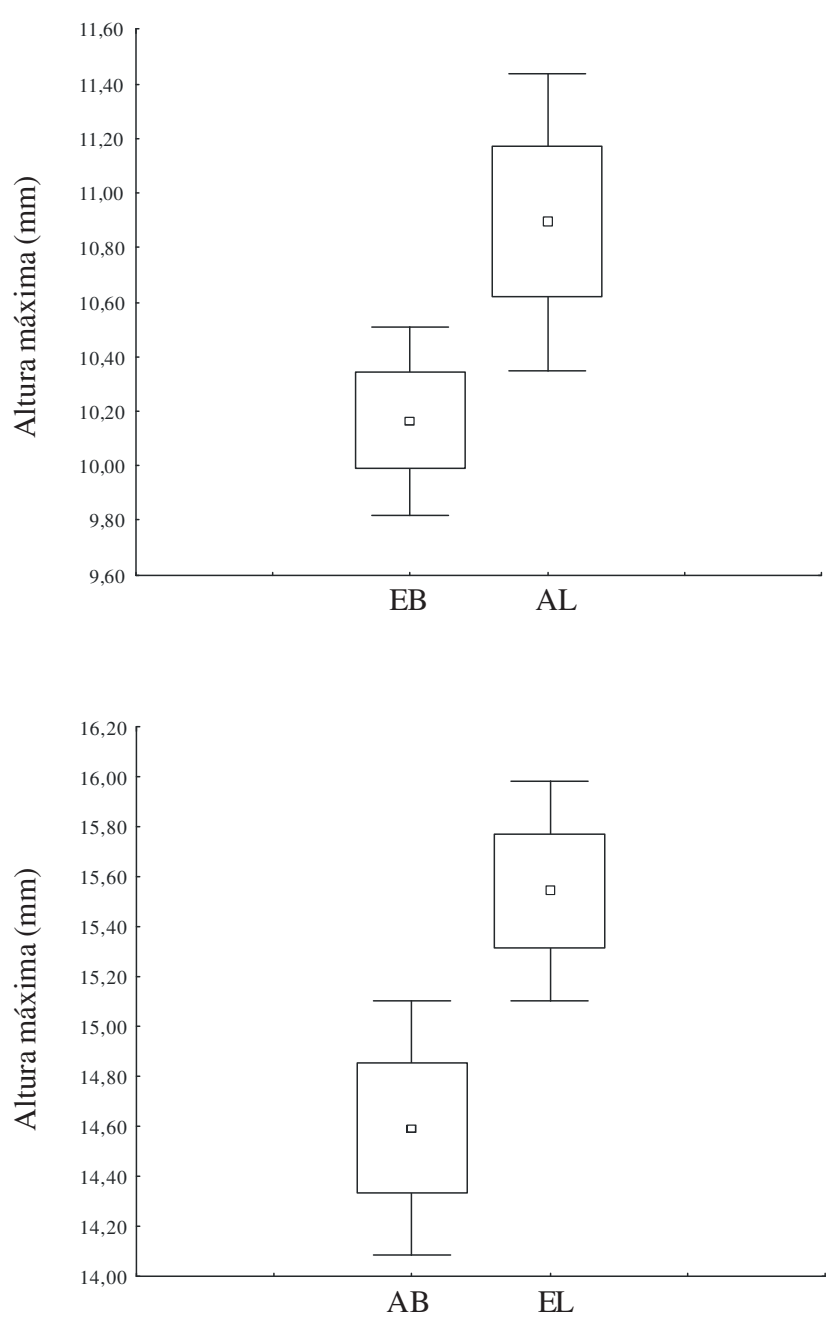

Figura 1. Representação das alturas máximas de anteras (A) e estigmas (E) das flores brevistilas (B) e longistilas (L) de Psychotria brachypoda (Müll. Arg.) Britton em área de Floresta Atlântica, Sudeste do Brasil. Foram medidas as alturas máximas de 37 anteras de flores brevistilas (AB), 43 longistilas (AL), 31 estigmas de flores longistilas (EL) e 44 brevistilas (EB). Quadrado central: média; quadrado maior: \pm erro padrão; extremos das barras verticais: intervalo de confiança de $95 \%$.

$3,16 \mu \mathrm{L} \pm 3,64(\mathrm{n}=30)$, e as que tiveram o néctar coletado apenas no final do dia produziram um volume aproximadamente três vezes menor $(1,18 \mu \mathrm{L} \pm 1,34$; $\mathrm{n}=26)$.

A floração ocorreu entre agosto e janeiro, com maior número de flores abertas em outubro nos dois anos do estudo. A frutificação ocorreu entre dezembro/2003 e julho/2004 e entre dezembro/2004 e junho/2005. Foram registrados frutos maduros de março a julho/2004 e de fevereiro a maio/2005 (Fig. 3).

Foram registradas 360 visitas ao longo do dia, incluindo 79 realizadas por machos e fêmeas do beijaflor Thalurania glaucopis Gmelim, 176 por abelhas 


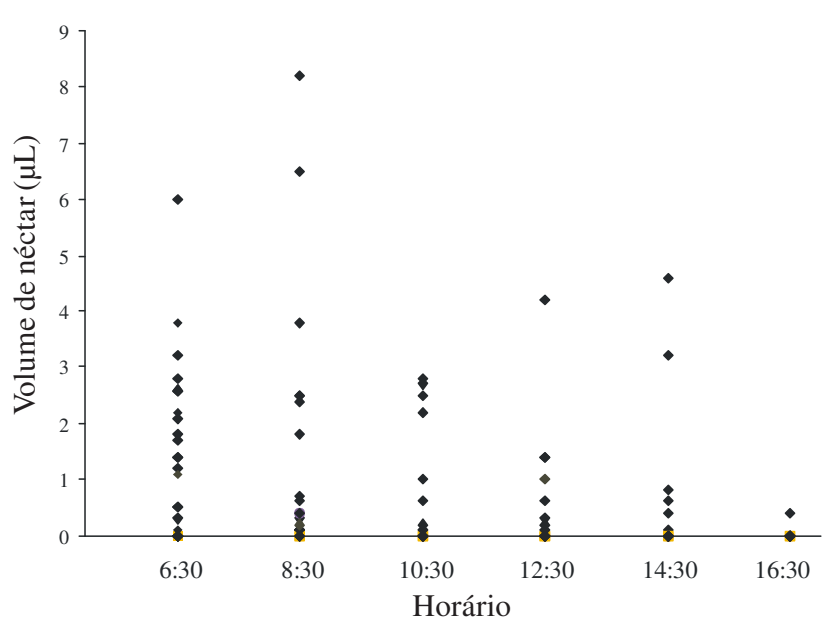

Figura 2. Volume de néctar $(\mu \mathrm{L})$ produzido ao longo do dia por 30 flores de Psychotria brachypoda (Müll. Arg.) Britton, em Floresta Atlântica, Sudeste do Brasil.

da tribo Trigonini, 36 por abelhas Euglossa, 48 por três espécies de lepidópteros, 12 por uma espécie de díptero e nove por um coleóptero. Machos e fêmeas de T. glaucopis realizaram visitas legítimas, ao longo do dia (Tab.1), contatando os estames e estigma das flores com o bico e visitaram dez indivíduos de P. brachypoda dentre os 12 amostrados. As abelhas Trigonini realizaram 176 visitas a sete plantas. Embora tenham realizado visitas legítimas em busca de néctar e coletado pólen, também pilharam néctar, furando a base da corola. Os dípteros, as abelhas do gênero Euglossa e os lepidópteros visitaram de forma legítima, porém realizaram poucas visitas. Os dípteros permaneceram muito tempo em cada flor e provavelmente não são polinizadores importantes para a espécie de planta estudada. As abelhas da tribo Trigonini foram os únicos visitantes florais que tiveram a sua atividade positivamente relacionada com a produção de néctar, sendo o número de visitas realizadas por estas abelhas uma função do volume de néctar produzido pelas flores amostradas ao longo do $\operatorname{dia}\left(Y=13,51+1,92 X ; r^{2}=0,973 ; p=0,0002 ; n=6\right)$.

Houve formação de frutos verdes em 13,3\% do total de flores marcadas $(\mathrm{n}=1409)$, sendo $13,7 \%$ em flores longistilas $(\mathrm{n}=771)$ e $12,7 \%$ em flores brevistilas $(n=638)$.

\section{Discussão}

O comprimento da corola das flores brevistilas foi maior do que o das flores longistilas. Este padrão é esperado para espécies distílicas com estames epipétalos (fixos diretamente no tubo da corola), como

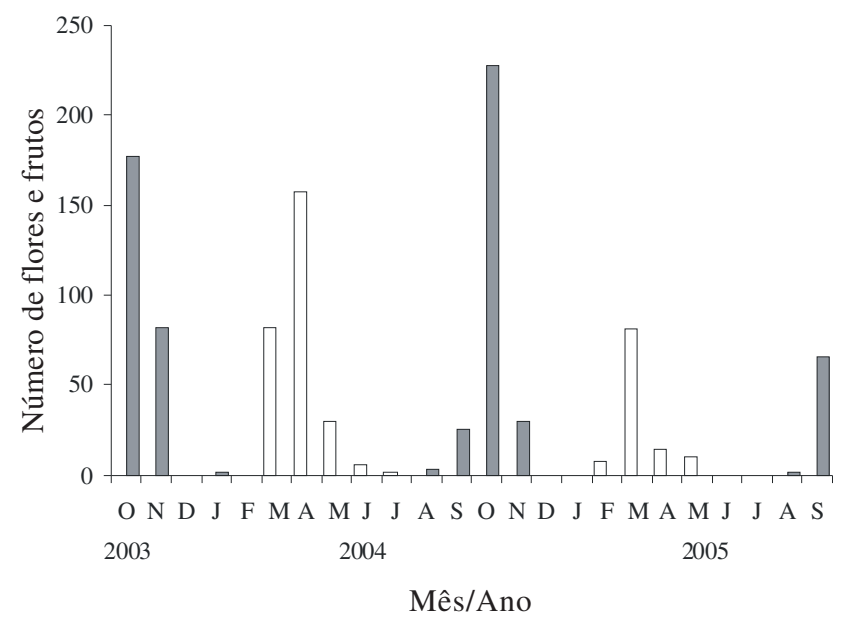

Figura 3. Número de flores abertas ( $\square$ ) e de frutos maduros ( $\square$ ) em 35 indivíduos de Psychotria brachypoda (Müll. Arg.) Britton, em área de Floresta Atlântica, Sudeste do Brasil.

Tabela 1. Porcentagem de flores de Psychotria brachypoda (Müll. Arg.) Britton visitadas ao longo do dia em 2003 , 2004 e 2005 em Floresta Atlântica, Sudeste do Brasil. ${ }^{a}$ T. gl= Thalurania glaucopis Gmelim

\begin{tabular}{|c|c|c|c|c|c|c|c|c|c|c|c|c|}
\hline \multirow[t]{2}{*}{ Visitantes } & \multicolumn{12}{|c|}{ Horário (h) } \\
\hline & 06:00 & 07:00 & 08:00 & 09:00 & $10: 00$ & 11:00 & $12: 00$ & 13:00 & $14: 00$ & $15: 00$ & $16: 00$ & $17: 00$ \\
\hline Coleóptero & 10 & 0 & 0 & 10 & 0 & 60 & 20 & 0 & 0 & 0 & 0 & 0 \\
\hline Díptero & 5 & 16 & 21 & 0 & 5 & 0 & 0 & 0 & 26 & 0 & 0 & 26 \\
\hline Euglossa sp. & 12 & 1 & 2 & 17 & 7 & 10 & 17 & 23 & 7 & 4 & 3 & 0 \\
\hline Lepidoptera 1 & 1 & 0 & 8 & 11 & 8 & 10 & 14 & 7 & 17 & 10 & 8 & 6 \\
\hline Lepidoptera 2 & 0 & 0 & 0 & 100 & 0 & 0 & 0 & 0 & 0 & 0 & 0 & 0 \\
\hline Lepidoptera 3 & 0 & 0 & 0 & 0 & 0 & 0 & 0 & 38 & 29 & 33 & 0 & 0 \\
\hline T.gl. fêmea ${ }^{\mathrm{a}}$ & 7 & 16 & 3 & 8 & 5 & 5 & 21 & 18 & 3 & 6 & 8 & 0 \\
\hline T.gl. macho & 8 & 6 & 5 & 7 & 16 & 8 & 14 & 5 & 7 & 8 & 10 & 5 \\
\hline Trigonini & 14 & 18 & 16 & 9 & 8 & 6 & 9 & 4 & 5 & 4 & 5 & 2 \\
\hline Total & 8 & 10 & 6 & 8 & 7 & 6 & 14 & 15 & 9 & 9 & 6 & 2 \\
\hline
\end{tabular}


os de P. brachypoda, pois corolas mais longas em flores brevistilas permitem que as anteras se localizem em um nível equivalente do estigma de flores longistilas (ver Pailler \& Thompson 1997).

O posicionamento recíproco dos estigmas e das anteras foi próximo, mas não perfeito. No entanto, a amplitude da altura das anteras brevistilas se sobrepôs à dos estigmas das flores longistilas e vice-versa. Além disso, não houve sobreposição entre a altura dos estigmas dos dois morfos florais nem entre a altura dos estames destes. Segundo Ganders (1979), em muitas espécies heterostílicas a correspondência recíproca nos comprimentos das anteras e estilete é muito próxima, embora não seja perfeita. Trabalhos realizados com outras espécies distílicas de Psychotria indicam que mesmo sem reciprocidade exata entre a altura de estames e estigmas dos morfotipos florais, pode haver um maior fluxo de pólen entre morfos diferentes, ou seja, maior número de cruzamentos legítimos (Favre \& McDade 2001; Castro \& Araújo 2004; Teixeira \& Machado 2004).

A proporção de 1:1 entre indivíduos brevistilos e longistilos geralmente é encontrada em populações de espécies distílicas (Monteiro et al. 1991; Pailler \& Thompson 1997; Richards \& Koptur 1993; Lau \& Bosque 2003; Teixeira \& Machado 2004). Esta proporção é esperada em populações totalmente auto - incompatíveis e que não tenham desvios no sucesso reprodutivo de nenhum dos morfos florais. Desvios desta razão podem ser encontrados em populações pequenas ou em espécies que se reproduzem predominantemente de forma vegetativa. A sobrevivência, a presença de auto - compatibilidade e o aborto seletivo de embriões são outras razões para a freqüência de morfos ser anisoplética (Ganders 1979).

A época de floração e de frutificação coincidiram com o reportado para esta espécie no litoral de São Paulo (SanMartin-Gajardo \& Morellato 2003). A floração foi do tipo anual e intermediária (cf. Newstrom et al. 1994), e ocorreu no início do período de maior precipitação, enquanto que os frutos maduros estiveram disponíveis no período de menor precipitação.

Assim como P. brachypoda, outras espécies de Psychotria também possuem visitantes florais de diversos táxons, como insetos e aves (Stone 1996; Almeida \& Alves 2000; Faivre \& McDade 2001; Castro \& Araújo 2004; Coelho \& Barbosa 2004; Teixeira \& Machado 2004; Ramos \& Santos 2005). A partir da quantidade de flores abertas por dia, do tamanho da corola e das características do néctar, as flores de $P$. brachypoda podem ser classificadas como "dispersas a moderadas" (sensu Feinsinger \& Colwell 1978) e não oferecem recurso suficiente para serem defendidas por beija-flores territoriais. Os dados do presente estudo corroboram com esta classificação já que fêmeas de T. glaucopis, que geralmente são parasitas de territórios ou forrageadoras em linhas de captura, visitaram mais flores do que os machos desta espécie, que freqüentemente defendem territórios que tenham recursos mais ricos (Canela \& Sazima 2003; Almeida 2005). É provável que o principal polinizador de P. brachypoda seja o beija-flor T. glaucopis devido à elevada frequiência de visitas legítimas, ao número de plantas visitadas (10/12) e ao seu comportamento de forrageio. Os beija-flores realizam visitas rápidas em cada indivíduo e podem voar por longas distâncias em pouco tempo (Gill 1985), visitando mais plantas do que visitantes que passam muito tempo em cada indivíduo. Esse comportamento pode favorecer a polinização cruzada (Canela \& Sazima 2003) em plantas distílicas (Stone 1996).

Em P. brachypoda os animais realizaram visitas ao longo do dia, não havendo uma predominância de visitas de manhã ou à tarde, apesar das medidas de néctar indicarem haver maior quantidade disponível na parte da manhã. Embora o número de flores visitadas pelos indivíduos da tribo Trigonini tenha sido relacionado com a secreção de néctar das flores de $P$. brachypoda, estes indivíduos foram categorizados como pilhadores de néctar pois retiraram néctar das flores de modo ilegítimo. Ao contrário de outros estudos com Psychotria que registraram estas abelhas como polinizadoras (Teixeira \& Machado 2004) ou pilhadoras e eventualmente polinizadoras (Almeida 2005), o presente estudo apenas registrou estas abelhas como pilhadoras. Em trabalhos onde houve uma relação entre a produção de néctar e as visitas de beija-flores, o volume de néctar secretado era maior do que o de P. brachypoda (Canela \& Sazima 2003; Longo \& Fischer 2006; Fischer \& Leal 2006). É possível que a baixa quantidade de néctar produzido por $P$. brachypoda não leve os beija-flores a modificar o seu comportamento de acordo com a sua produção e que estes animais tenham o seu comportamento de forrageamento influenciado por plantas que possuem maior volume de néctar.

A maior produção de néctar entre flores que foram manipuladas ao longo do dia em comparação com aquelas em que o recurso só foi retirado ao final do dia pode ter ocorrido devido à reabsorção 
do néctar pelas últimas. A reabsorção do néctar permite que a planta economize recursos importantes que não foram utilizados pelos polinizadores (Burquez \& Corbet 1991; Luyt \& Johnson 2002). Outra possibilidade é que as flores desta espécie sejam estimuladas a produzir mais néctar conforme este recurso seja retirado pelos visitantes florais (Gill 1988; Galetto \& Bernardello 1992). Neste caso, a produção de néctar pode ter sido subestimada, já que este foi retirado a cada duas horas e as flores foram visitadas em todos os horários de observação, ou seja, pelo menos uma vez por hora.

Estudos com plantas distílicas indicam que há um fluxo assimétrico de pólen entre os morfotipos florais (Ganders 1979; Stone 1996; Lau \& Bosque 2003) que pode favorecer a formação de frutos em flores brevistilas (Teixeira \& Machado 2004; Ornelas et al. 2004) ou longistilas (Monteiro et al. 1991; Pailler \& Thompson 1997). Em P. brachypoda, como a taxa de frutos foi semelhante entre os morfotipos florais, parece não ter havido fluxo preferencial de pólen entre eles. Este resultado indica que o comportamento dos polinizadores foi eficiente do ponto de vista da planta, para a transferência de pólen entre os morfotipos. É possível que a produção prolongada de néctar seja uma estratégia da planta para favorecer a visitação às flores ao longo do dia (Heinrich \& Raven 1972), aumentando a transferência de pólen por diferentes espécies animais.

\section{Agradecimentos}

Ao pessoal do Centro de Estudos Ambientais e Desenvolvimento Sustentável (CEADS/UERJ); à Fundação Instituto de Desenvolvimento Econômico e Social do Rio de Janeiro, que forneceu os dados climáticos; ao Sebastião José da Silva Neto que identificou a espécie de planta; à Leila Morgado, que identificou as abelhas Euglossa e tribo Trigonini; à Ângela Detweiler pela revisão do abstract; aos dois revisores anônimos, cujas contribuições melhoraram muito o manuscrito; à Ideawild que forneceu material de campo; ao Conselho Nacional de Desenvolvimento Científico e Tecnológico (CNPq) pela concessão de bolsa de mestrado para L.C.N. Fonseca e pela Bolsa de Produtividade em Pesquisa para M.A.S. Alves (processo n· 302718/03-6), à qual está vinculado um financiamento à pesquisa utilizado no presente trabalho; e à Capes pela bolsa de doutorado para E.M. Almeida.

\section{Referências bibliográficas}

Almeida, E.M. 2005. Ecologia reprodutiva e comportamento dos visitantes florais e dos frugívoros em duas espécies de Psychotria L. (Rubiaceae) em uma área de Floresta Atlântica, Ilha Grande, Rio de Janeiro. Tese de Doutorado. Universidade do Estado do Rio de Janeiro. Almeida, E.M. \& Alves, M.A.S. 2000. Fenologia de Psychotria nuda e P. brasiliensis (Rubiaceae) em uma área de Floresta Atlântica do sudeste do Brasil. Acta Botanica Brasilica 14: 335-346.

Araujo, D.S.D. \& Oliveira, R.R. 1988. Reserva Biológica Estadual da Praia do Sul (Ilha Grande, Estado do Rio de Janeiro): lista preliminar da flora. Acta Botanica Brasilica 1: 83-94.

Barrett, S.C. 1992. Heterostylous genetic polymorphisms, model systems for evolutionary analysis. Pp. 1-29 In: S.C.H. Barrett (ed.). Evolution and Function of Heterostyly. Berlim, Springer-Verlag..

Barret, S.C.; Jesson, L.K. \& Baker, A.M. 2000. The evolution and function of stylar polymorphisms in flowering plants. Annals of Botany 85: 253-265.

Burquez, A. \& Corbet, A. 1991. Do Flowers Reabsorb Nectar? Functional Ecology 5: 369-379.

Castro, C.C. \& Araújo, A.C. 2004. Distyly and sequential pollinators of Psychotria nuda (Rubiaceae) in the atlantic rain forest, Brazil. Plant Systematic Evolution 244: 131-139.

Castro, C.C. \& Oliveira, P.E. 2002. Pollination biology of distylous Rubiaceae in the atlantic rain forest, SE Brazil. Plant Biology 4: 640-646

Coelho, C.P. \& Barbosa, A.A.A. 2003. Biologia reprodutiva de Palicourea macrobotrys Ruiz \& Pavon (Rubiaceae): um possível caso de homostilia no gênero Palicourea Aubl. Revista Brasileira de Botânica 26: 403-413.

Coelho, C.P. \& Barbosa, A.A.A. 2004. Biologia reprodutiva de Psychotria poeppigiana Mull Arg (Rubiaceae) em mata de galeria. Acta Botanica Brasilica 18: 481-489.

Faivre, A.M. \& McDade, L.A. 2001. Population-level variation in the expression of heterostyly in three species of Rubiaceae: does reciprocal placement of anthers and stigmas characterize heterostyly? American Journal of Botany 88: 841-843.

Feinsinger, P. \& Colwell, R. 1978. Community organization among neotropical nectar-feeding birds. American Zoologist 18: 779-795.

Fischer, E. \& Leal, I.R. 2006. Effect of nectar secretion rate on pollination success of Passiflora coccinea (Passifloraceae) in the central Amazon. Brazilian Journal of Biology 66: 747-754.

Galetto, L. \& Bernardello, L.1992. Nectar secretion pattern and removal effects in six Argentinean Pitcairnioideae (Bromeliaceae). Botanica Acta 105: 292-299.

Ganders, F.R. 1979. The biology of heterostyly. New Zealand Journal of Botany 17: 607-635.

Gentry, A.H. \& Emmons, L.H. 1987. Geographical variation in fertility, phenology and composition of the understory of neotropical forests. Biotropica 19: 216-227. 
Gill, F.B. 1985. Hummingbird flight speeds. The Auk 102: 97-101.

Gill, F.B. 1988. Effects of nectar removal on nectar accumulation in flowers of Heliconia imbricata (Heliconiaceae). Biotropica 20: 169-171.

Grantsau, R. 1989. Os beija-flores do Brasil. Rio de Janeiro, Editora Expressão e cultura.

Hamilton, C.W. 1990. Variation on a distylous theme in Mesoamerican Psychotria subgenus Psychotria (Rubiaceae). Memoirs of The New York Botanical Garden 55: 62-75.

Heinrich, B. \& Raven, P.A. 1972. Energetics and pollination ecology. Science 176: 597-602.

Laska, M.S. 1997. Structure of understory shrub assemblages in adjacent secondary and old growth tropical wet forests, Costa Rica. Biotropica 29: 29-37.

Lau, P. \& Bosque, C. 2003. Pollen flow in the distylous Palicourea fendleri (Rubiaceae): an experimental test of the dissortative pollen flow hypothesis. Oecologia 153: $593-600$.

Leal, M.B. \& Elisabetsky, E. 1996. Opioid-like activity of Psychotria brachypoda. Pharmaceutical Biology 34: 267-272.

Lopes, L.E. \& Buzato, S. 2005. Biologia reprodutiva de Psychotria suterella Muell. Arg. (Rubiaceae) e a abordagem de escalas ecológicas para a fenologia de floração e frutificação. Revista Brasileira de Botânica 28: 785-795.

Longo, M.L. \& Fischer, E. 2006. Efeito da taxa de secreção de néctar sobre a polinização e a produção de sementes em flores de Passiflora speciosa Gardn. (Passifloraceae) no Pantanal. Revista Brasileira de Botânica 29: 481-488.

Luyt, R. \& Johnson, S.D. 2002. Postpollination nectar reabsorption and its implications for fruit quality in an epiphytic orchid. Biotropica 34: 442-446.

Monteiro, R.; Nakajima, J.N.; Ribeiro, J.E.L.S. \& Toledo, J.C. 1991. Morfologia e distribuição espacial das formas heterostílicas de Psychotria barbiflora D.C. (Rubiaceae). Naturalia 16: 137-146.

Morellato, L.P.C. \& Leitão Filho, H.F. 1992. Padrões de frutificação e dispersão na Serra do Japi. Pp. 112-140. In: L.P.C. Morellato (org.). História Natural do Japi: Ecologia e Preservação de uma Área Florestal no Sudeste do Brasil. Campinas, Editora da Unicamp.
Newstrom, L.E.; Frankie, G.W. \& Baker, H.G. 1994. A new classification for plant phenology based on flowering patterns in lowland tropical rain forest at La Selva, Costa Rica. Biotropica 26: 141-159.

Oliveira, R.R. 2002. Ação antrópica e resultantes sobre a estrutura e composição da Mata Atlântica na Ilha Grande, RJ. Rodriguésia 53: 33-58.

Ornelas, J.F.; González, C.; Jiménez, L.; Lara, C. \& Martinez, A.J. 2004. Reproductive ecology of distylous Palicourea padifolia (Rubiaceae) in a tropical montane cloud forest. II. Attracting and rewarding mutualistic and antagonistic visitors. American Journal of Botany 91: 1061-1069.

Pailler, T. \& Thompson, J.D. 1997. Distyly and variation in heteromorphic incompatibility in Gaertnera vaginata (Rubiaceae) endemic to La Reunion Island. American Journal of Botany 84: 315-327.

Pereira, O.J. \& Araujo, D.S.D. 2000. Análise florística das restingas dos Estados do Espírito Santo e Rio de Janeiro. Pp. 25-63. In: F.A. Esteves \& L.D. Lacerda (eds.). Ecologia de Restingas e Lagoas Costeiras. Macaé, NUPEM/ UFRJ.

Ramos, F.N. \& Santos, F.A.M. 2005. Phenology of Psychotria tenuinervis (Rubiaceae) in Atlantic forest fragments: fragments and habitat scales. Canadian Journal of Botany 83: 1305-1316.

Ramos, F.N. \& Santos, F.A.M. 2006. Floral Visitors and Pollination of Psychotria tenuinervis (Rubiaceae): Distance from the Anthropogenic and Natural Edges of an Atlantic Forest Fragment. Biotropica 38: 383-389.

Richards, J.H. \& Koptur, S. 1993. Floral variation and distyly in Guettarda scraba (Rubiaceae). American Journal of Botany 80: 31-40.

SanMartin-Gajardo, I. \& Morellato, L.P.C. 2003. Fenologia de Rubiaceae do sub-bosque em Floresta Atlântica no sudeste do Brasil. Revista Brasileira de Botânica 26: 299-309.

Stone, J.L. 1996. Components of pollination effectiveness in Psychotria suerrensis, a tropical distylous shrub. Oecologia 107: 504-512.

Teixeira, L.A.G. \& Machado, I.C. 2004. Biologia da polinização e sistema reprodutivo de Psychotria barbiflora DC. (Rubiaceae). Acta Botanica Brasilica. 18: $853-862$.

Zar, J.H. 1999. Biostatistical Analysis. $4^{\text {th }}$ ed. New Jersey, Prentice-Hall. 